\title{
"Clean, Green and Ethical" Animal Production. Case Study: Reproductive Efficiency in Small Ruminants
}

\author{
Graeme B. MARTIN ${ }^{1)}$ and Hiroya KADOKAWA ${ }^{2)}$ \\ 1) School of Animal Biology, Faculty of Natural \& Agricultural Sciences, The University of \\ Western Australia, Crawley 6009, Western Australia, Australia and ${ }^{2)}$ Department of Animal \\ Breeding and Reproduction, National Institute of Livestock and Grassland Science, \\ Senbonmatsu 768, Nasushiobara, Tochigi 329-2793, Japan
}

\begin{abstract}
In response to changes in society and thus the marketplace, we need a vision for the future of our animal industries, including both on-farm and off-farm activities, that is "clean, green and ethical". Using small ruminants as a case study, we describe three "clean, green and ethical" strategies that farmers could use to improve reproductive performance. The first allows control of the timing of reproductive events by using socio-sexual signals (the "male effect") to induce synchronised ovulation in females. The second strategy, "focus feeding", is based on using short periods of nutritional supplements that are precisely timed and specifically designed for each event in the reproductive process (eg, gamete production, embryo survival, fetal programming, colostrum production). The third strategy aims to maximize offspring survival by a combination of management, nutrition and genetic selection for behaviour (temperament). All of these approaches involve non-pharmacological manipulation of the endogenous control systems of the animals and complement the detailed information from ultrasound that is now becoming available. Importantly, these approaches all have a solid foundation in reproductive biology. In several cases, they are currently used in commercial practice, but there is still room for improvement through both basic and applied research. Ultimately, these "clean, green and ethical" tools can be cost-effective, increase productivity and, at the same time, greatly improve the image of meat and milk industries in society and the marketplace.
\end{abstract}

Key words: Male effect, Nutrition, Colostrum, Temperament

(J. Reprod. Dev. 52: 145-152, 2006)

\section{Background}

Animal industries around the world are being challenged by changing attitudes in consumers that are having an impact in the marketplace: there is an increasing demand for products that are "clean, green and ethical". For farmers, this need not be difficult because, as we work towards a better understanding of the physiology and behaviour of our farm animals, we can improve productivity and profitability and, simultaneously, promote

Correspondence: G.B. Martin

(e-mail: gmartin@animals.uwa.edu.au) "clean, green and ethical" production. What do these three words signify?

\section{Clean}

We should look for practices in the industry where drugs, chemicals and hormones are used, and try to find ways to reduce the usage and, perhaps, eliminate it. There is little doubt that, in general, this demand is driven by market forces that are not themselves generated by scientific argument-hormonal treatments rarely leave residues, especially after withholding periods, and it is relatively easy to demonstrate that products 
from animals that have not been treated with exogenous hormones can contain significant amounts of the same hormone (eg, steroids in cow's milk). The positive aspect of the demand for "clean" products is that the demand comes from modern, high-priced markets where farmers can make large profits (eg, the market for "organic" products).

\section{Green}

We should consider the impact of the industry on the environment, with the aim of minimising the impact and making the industry more sustainable for the long-term future. On farms, the most important issues are the production of greenhouse gases by ruminants, the production of animal waste (especially for intensive industries), and the excessive use of fertilisers to generate animal feeds. The need to minimise environmental impact also applies to the allied industries....those that participate in the processing of the products from the farm (eg, transport, abattoirs, milk factories). Again, if we can say that our industry is "green", it will help with the marketing in highly developed economies and, at the same time, guarantee the long-term future of the industry.

\section{Ethical}

Here, the obvious focus is the attitude of the industry to the animals themselves. 'Animal welfare' is a major concern for all industries that are working in sophisticated markets, where the consumers expect their products to be derived from animals that have been managed sympathetically. This can be a complex issue because, by pursuing a 'clean' image and avoiding the use of antibiotics, for example, we may compromise the welfare of the animals. In addition, the application of ethical judgement needs to be broader than simply animal management: as well as the practices in animal management on farms, it should include 'clean' and 'green' aspects of the transport, manufacturing and processing sectors-the processing, packaging and marketing of the products.

\section{Case Study: Reproduction in Small Ruminants}

The productivity and profitability of our meat and milk industries effectively depend on reproductive performance. We can greatly improve reproductive output with exogenous hormone regimens or high-level reproductive technology and molecular genetics. These technologies are remarkable and effective, but we need to find alternatives so we can cope with the changes in consumer sentiment. In addition, these technologies have little direct, short-term benefit for animal industries that are based on extensive management or in developing economies. Most small ruminants around the world are used in extensive production systems in which high-level technologies are not likely to make an impact in the near future $[1,2]$.

Our Approach: We have chosen to concentrate on the natural control systems that the animals themselves use to cope with environmental challenges and ensure reproductive success [1]. Most important here are inputs from the external environment: photoperiod, socio-sexual stimuli and nutrition. Most reproductive responses to environmental factors are coordinated at brain level where all external and internal inputs ultimately converge into a common pathway that controls the secretion of gonadotrophin-releasing hormone (GnRH; Fig. 1).

This mix of endogenous inputs into the control of the reproductive system provides us with major opportunities for management of reproductive efficiency. First, to control the timing of reproductive events, we can use socio-sexual signals (the male effect) to induce synchronised ovulation in females that would otherwise be anovulatory. Second, in focus feeding, we can use the responses to nutrition to design nutritional supplements that are aimed precisely and specifically at each individual event in the reproductive process. The third and final strategy, maximising the survival and development of the newborn, involves a mix of environmental management, nutrition and genetic selection.

\section{1) Control of the timing of reproductive events}

Two aspects of timing cause problems for the industry by preventing the producers from deciding when their animals will conceive: seasonal breeding and postpartum anoestrus. In both situations, the lack of ovulation is due to lack of GnRH output. This means that exogenous hormones can be used very effectively to overcome the problem in most circumstances. 


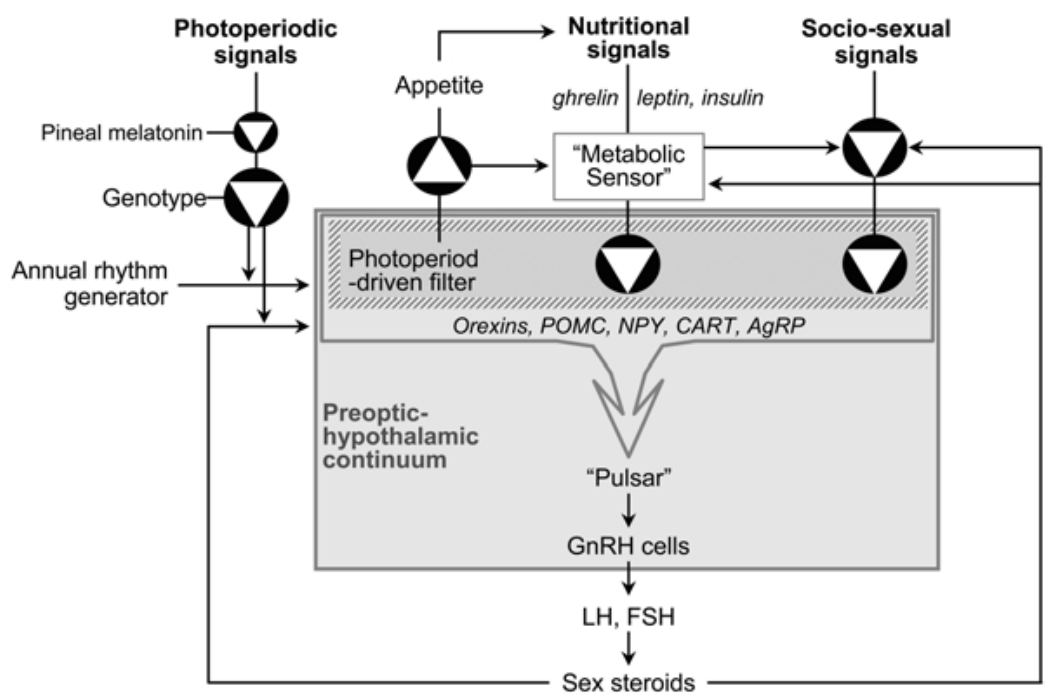

Fig. 1. Environmental inputs into reproduction operate through a variety of pathways, many of which ultimately affect the "pulsar" [3] that controls the pulsatile secretion of gonadotrophin-releasing hormone $(\mathrm{GnRH})$. The relative strength of the responses to photoperiod, nutritional and sociosexual stimuli depends on genotype. The socio-sexual signals seem to work mainly through the main olfactory system, but little work has been done on the roles of the visual and auditory stimuli in the induction of ovulation in sheep and goats [4]. Nutritional signals are also received at brain level $[5,6]$, but there are also nutritional and metabolic inputs into uterine and mammary function that affect reproductive success. POMC: pro-opiomelanocortin. AgRP: Agouti-related peptide. Modified after Blache et al. 2003 [6].

\section{The hormone option}

Inadequate endocrine drive can be circumvented by a carefully managed series of treatments including an implant or intravaginal device containing progesterone (and perhaps oestrogen) followed by injections of gonadotrophins. These treatments are now highly developed for different species and different situations and the time of breeding can be controlled very precisely (within hours). For seasonally anovulatory animals, melatonin is also available and it has a major advantage in that it only requires a single treatment (a subcutaneous implant), about 6 weeks ahead of the desired time of mating.

Within the context of this paper, none of the hormonal treatments are "clean". They may also not be "green" - there is a perceived risk associated with liberation of sex steroids into the environment with the disposal of used intravaginal devices. There are also issues of expense: such treatments are too costly for small producers in developing countries and the labour costs incurred are too great for producers with large extensive flocks. The melatonin implant has another disadvantage in that it provides much less precision over the time of breeding. As we shall see below, this is a major impediment for the implementation of focus feeding because supplements may need to be fed for very short periods during very specific parts of the reproductive process. To do this, we need an efficient, non-pharmacological method for accurately controlling the timing of reproductive events.

\section{Alternatives for overcoming seasonal breeding a) Changing the nightlength}

This option is particularly attractive for small producers from developing countries because it requires a very small investment. However, as with melatonin, there are limits to the possibilities for focus feeding because the females would begin to cycle over a range of days or even weeks. It is a far more attractive proposition for treating males so that their reproductive axis is working at maximum 
efficiency when they are used for the male effect [7].

\section{b) The male effect}

In sheep and goats, the sudden introduction of novel males can induce ovulation in females that are reproductively quiescent because they are out of season or lactating (reviews: [8-11]). Induced ovulations are sufficiently synchronised among a group of females to allow the use of strategies such as focus feeding (see below) to improve litter size, fetal programming and neonatal survival. The male effect has the added advantage that it allows control over the season of births so that producers can take advantage of seasonal markets. In addition to interrupting seasonal anoestrus, it can shorten post-partum anoestrus in sheep, goats and cattle $[7,12,13]$.

The male effect is not perfect, even in the most favourable situations: for example, the Merino is among the best ovine genotypes for the response but $5-20 \%$ of ewes do not respond, the first ovulation is not accompanied by oestrus and, in about half of the ewes, the first cycle will be short (about 6 days) so there is some loss of synchrony in the flock $[3,8]$. The areas where we need basic research have recently been reviewed in detail [4] and include:

- The neural and neuroendocrine mechanisms involved;

- Variations in the ovulatory responses of the female;

- The lack of response during the breeding season;

- The poor response in many genotypes (eg, Suffolk).

\section{c) Ultrasound}

Skilled operators with modern instruments can provide two important types of information. First, the identification of single-bearing and multiplebearing females so we can use specific strategies to manage their different requirements during pregnancy and after parturition. Second, accurate estimation of the age of a fetus [eg, 14] so we can use precisely timed nutritional supplements during fetal development (see below). Another very important contribution will be made in research into the physiological processes involved in the male effect. Ultrasound technology allows us to study ovarian follicles during their preovulatory growth and during their postovulatory transformation. This development is set to continue and perhaps enter a new phase with the advent of colour imaging of follicles that the changes in their blood supply (A Miyamoto, these proceedings).

\section{2) Nutrition-the concept of 'Focus feeding'}

For all animal enterprises, feed is the primary limiting resource and there is constant economic pressure to reduce the amount used and then to ensure that, when used, it provides the greatest benefit. Strategic use of nutritional supplements has long been an important management tool in production systems but recent research suggests that we should focus on boosting sperm production before mating, maximising potential litter size (ovulation rate), avoiding embryo loss, programming the future productivity of the offspring, and maximizing postnatal survival and development (Fig. 2). For each period of focus feeding, we need to consider both the composition and duration of the diet so they are cost-effective for the management system because the degrees of focus will vary between enterprises and between environments. At any or all of these times, we could use conserved or stored feed or we could shift the entire reproductive process so that the critical periods are aligned with peaks and troughs in the availability of pasture.

\section{a) Boost sperm production}

Feeding males a supplement for 8 weeks before mating will ensure maximum testicular size and sperm production ([review: [15]). An important issue here is the concept of "fit but not fat" - males that are overweight and do not get exercise can perform poorly, even when they have maximum testicular mass [16].

\section{b) Maximize potential litter size (ovulation rate)}

The upper limit of prolificacy is determined by the number of ova released at ovulation and, in small ruminants, this is usually within the range 13. This limit to productivity has long been recognised and has driven a lot of research for most of the previous century.

\section{The hormone option}

A very large amount of research has been done on ways to increase ovulation rate with exogenous gonadotrophins, beginning with the discovery of the powers of serum from pregnant mares [17]. 


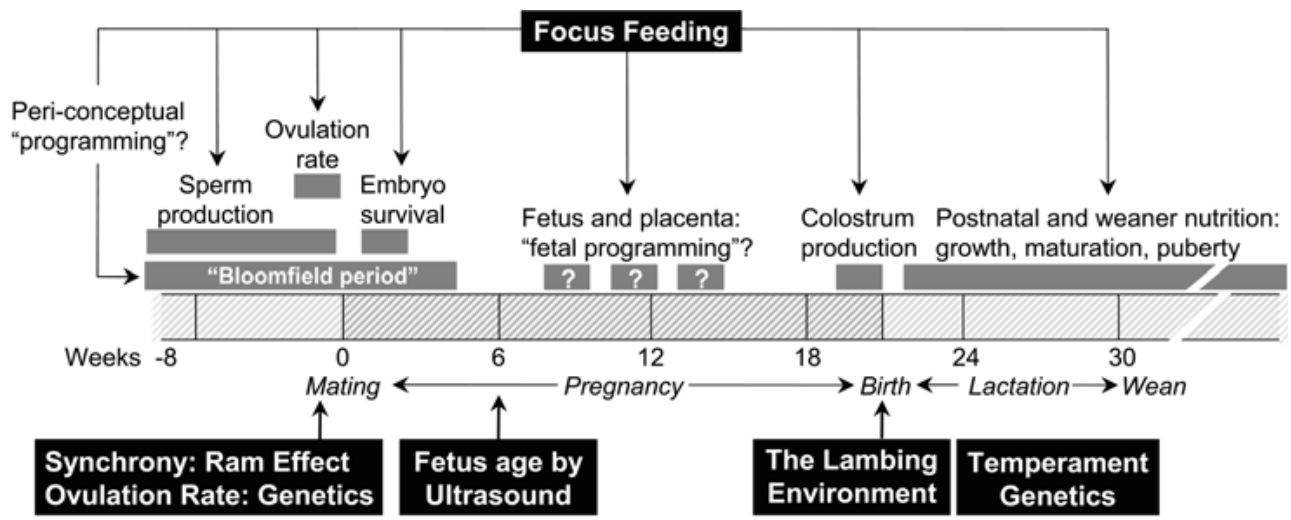

Fig. 2. A "Clean-Green-Ethical Package" for managing reproduction in goats and sheep: periods of focus feeding are used to control the reproductive process, mostly to improve the reproductive success of the flock or herd; the only exception is the possibility that overfeeding in the first 2 weeks after mating can provoke embryo mortality (this has only been tested in sheep). Mild undernutrition during the "Bloomfield Period" (15\% loss of body mass) can cause premature births in sheep (not tested in goats). To accurately time the periods of feeding, mating must be controlled and brief, or ultrasound must be used to classify the mothers based on the age of their fetuses. Finally, the survival of the new-born must be maximised by a combination of good genetics and good management. Redrawn after Martin et al. $[2,4]$.

The aim of much of this research was to provide large numbers of ova from each cycle for embryo transfer programs to increase the rate of genetic gain. Some effort was made to achieve the reliable, modest increases needed to improve ovulation rate within the constraints of the capacity of the uterus, but these treatments also require exogenous progestagen to control the cycle, so they are too expensive, in terms of the product and the labour, for more extensive management options. They are also not "clean and green".

A potentially attractive alternative is the use of immunisation against ovarian hormones, as initially proposed by Scaramuzzi and colleagues in 1977 [18]. This concept has two advantages: first, the increase in ovulation rate is modest so does not cause infertility; second, after the first year, it requires only a single booster injection to maintain the response. There may be some debate about whether this use of vaccination can be classified as "clean and green". Immunisation against inhibin has been used for the same purpose [19] but there has been less development of the product. At the time of writing, there is no commercial product for inhibin and the product based on steroids $\left(\right.$ Ovastim $\left.^{\circledR}\right)$ has not been a major success, perhaps due to problems with marketing and regulations for animal treatments.

\section{An alternative}

For a given female, the upper limit of ovulation rate is determined genetically and so can be improved through selection, but the expression of that genetic potential is influenced greatly by the nutritional regime before mating [reviews: 20, 21]. This is evident from the correlations between body condition and litter size but, more importantly in the context of focussed feeding, there is also an acute effect-feeding a supplement for as little as 4 days in the final stages of the oestrous cycle will increase the frequency of twin ovulations by 20$30 \%$ [22]. This effect will be used widely after it becomes sufficiently reliable. We need research because we still do not fully understand how nutrition affects the processes in the animal that control ovulation rate. Again, the chances of success have been markedly improved by the advent of sensitive ultrasound techniques and the development of colour imaging offers more opportunities [A Miyamoto these proceedings].

\section{c) Avoid early embryo loss}

Undernutrition is one of the many factors suggested as a cause for embryo loss [eg, 23]. Paradoxically, there is also evidence that overfeeding can cause early embryo mortality. This has been explained by an increase in the clearance of 
progesterone [24] but other factors, such as ammonia build up due to excessive intake of protein need investigation. This whole area is obviously fundamental to the implementation of focus feeding because there may be a conflict between strategies used to increase ovulation rate and strategies that promote early embryo survival. Moreover, over-feeding and under-feeding during early embryonic development may have long-term consequences for the embryos that survive because of the phenomenon of 'oocyte programming' (JG Thompson, these proceedings). Undoubtedly, more research is needed to test a wider range of types, times and durations of supplements and to develop nutritional strategies that avoid these problems.

A further complication has been revealed by a study showing that underfeeding ewes from 60 days before until 30 days after conception (the "Bloomfield Period" in Fig. 2) can cause very premature births [25]. Remarkably, the underfeeding was not severe (the ewes only lost $15 \%$ of their body mass) and all ewes had regained normal body mass at the time of parturition. We do not know the mechanisms involved.

d) Fetal programming - the future productivity of the offspring

It is important not to ignore the nutritional requirements for the development of the placenta [review: 26] as well as any critical periods during the development of the fetal organs between Days 60 and 120 of pregnancy. The consequences of maternal malnutrition on the fetus may not become evident until much later, after birth or even after sexual maturity, by which time the link between cause and effect will have been clouded. At least three aspects of sheep production are already known to be affected by nutrition during pregnancy [review: 2]: i) the initiation and development of secondary follicles in the skin; ii) the inhibitory effects of undernutrition during gestation on muscle fibre formation; iii) the development of the reproductive axis. At this stage, too little research has been done for us to know whether these types of effects can permanently compromise animal productivity.

\section{3) Maximising the survival and development of the offspring}

The obvious economic benefit of ensuring the survival of the offspring is return on investments in other aspects of the reproductive process. In addition, there is little doubt that, in the future, it will be seen as unethical to promote high birth rates if our management systems are inadequate to ensure that most of the new-born survive and prosper. There are four avenues of improvement: a) feed supplements that will improve colostrum production; b) genetically improve the temperament of females so they are better suited to motherhood; c) manage flocks during birth so that the formation of the mother-young bond is promoted, not disrupted [review: 27].

\section{a) Colostrum production and lamb survival}

An energy supplement given in the last week of gestation can more than double the volume of colostrum available to lambs at the moment of birth [28]. In addition to the nutritional and immunological benefits, a large volume of a full quota of colostrum in the gut improves the ability of a lamb to recognise its mother and therefore contributes to the early establishment of the ewelamb bond [29]. The outcome is better survival of the new-born [30].

\section{b) Selection of animals for "calm temperament"}

It is now clear that improvements in the temperament of mothers may increase offspring survival. For example, Murphy et al. [31] measured temperament of sheep, used it for genetic selection, and found that the mortality of twin lambs was $16 \%$ in calm ewes and $26 \%$ in nervous ewes. Many other aspects of animal productivity might also be improved by genetic selection for calm temperament [review: 3]: ovulation rate, mating success, embryo survival, sexual behaviour, growth rate; meat quality, and immune function. Milk quality is also improved (Fig. 3). Research into these outcomes, leading to widespread adoption of selection for temperament, should improve productivity while giving our industries an ethical quality. Effectively, we would be selecting animals that are more resistant to stress.

\section{c) Better management practices at birth}

We can improve several aspects of the behaviour of producers that will also improve the survival of the new-born. For example, it is important to provide a calm environment, and shelter, feed and water close to the birth site. This increases the 

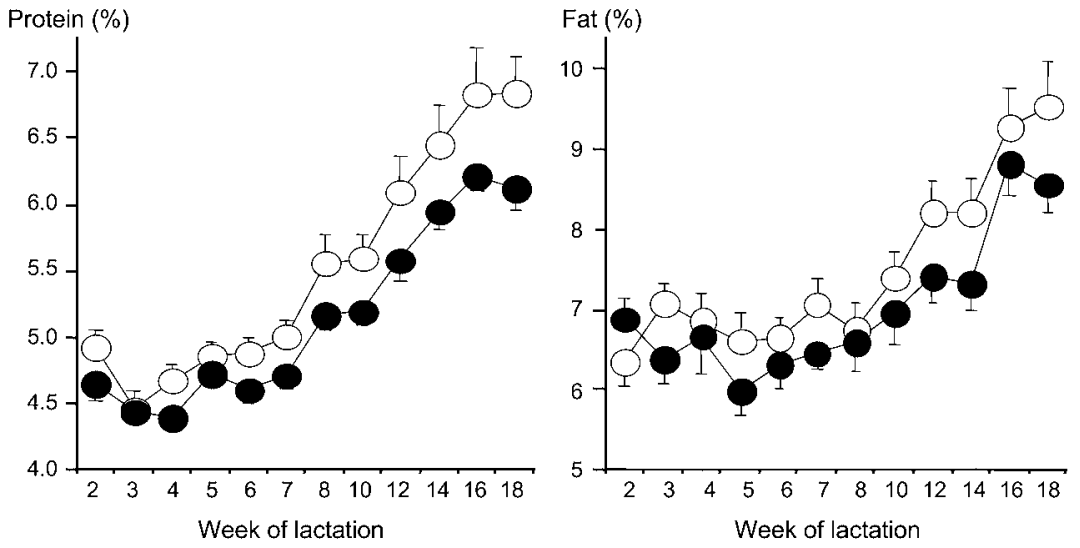

Fig. 3. Milk composition (mean \pm sem) in Merino ewes that have been classified as 'calm' ( $\mathrm{n}=14$, white symbols) or 'nervous' ( $\mathrm{n}=16$, black symbols). The concentration of protein was higher $(\mathrm{P}=0.03)$ in the milk produced by calm sheep compared with milk from nervous sheep. The difference in fat concentration was not significant $(\mathrm{P}=0.17)$. Preliminary data from the study of Sart et al. [32].

amount of time spent at the birth site and therefore improves the development of the mother-young bond [27].

\section{Conclusions}

Understanding the reproductive responses of animals to exteroceptive factors, such as photoperiod, nutrition, socio-sexual signals and stressors, can help us develop 'natural systems' as replacements for exogenous hormones and drugs for controlling and improving the productivity of our sheep and goats [1,2]. In addition, we can easily genetically improve our animals (eg, ovulation rate, calm temperament) to greatly improve many aspects of their productivity. The use of such 'clean, green and ethical' tools in the management of our animals can be cost-effective and improve profits, at the same time greatly improving the image of our industries in society and the marketplace. All we need is a little more research and development.

\section{References}

1. Martin GB. Reproductive research on farm animals for Australia-some long-distance goals. Reprod Fertil Dev 1995: 7; 967-982.

2. Martin GB, Milton JTB, Davidson RH, Banchero Hunzicker GE, Lindsa, DR, Blache D. Natural methods of increasing reproductive efficiency in sheep and goats. Anim Reprod Sci 2004: 82-83; 231246.

3. Martin GB. Factors affecting the secretion of luteinizing hormone in the ewe. Biol Rev 1984: 59; 187.

4. Martin GB, Rodger J, Blache D. Nutritional and environmental effects on reproduction in small ruminants. Reprod Fertil Develop 2004: 16; 491-501.

5. Zhang $S$, Blache $D$, Vercoe PE, Adam CL, Blackberry MA, Findlay PA, Eidne KA, Martin
GB. Expression of orexin receptors in the brain and peripheral tissues of the male sheep. Regulat Pept 2004: 124; 81-87.

6. Blache D, Zhang, S Martin GB. Fertility in males: modulators of the acute effects of nutrition on the reproductive axis of male sheep. Reproduction 2003 61 (Suppl): 387-402.

7. Delgadillo JA, Flores JA, Véliz FG, Hernández HF, Duarte G, Vielma J, Poindron P, Chemineau P, Malpaux B. Induction of sexual activity of lactating anovulatory female goats using male goats treated only with artificial long days. J Anim Sci 2002: 80; 2780-2786.

8. Martin GB, Oldham CM, Cognié Y, Pearce DT. The physiological responses of anovulatory ewes to the introduction of rams-a review. Livestock Prod Sci 
1986: 15; 219-247.

9. Walkden-Brown SW, Martin GB, Restall BJ. Role of male-female interaction in regulating reproduction in sheep and goats. J Reprod Fertil 1999: 52 (Suppl) ; 243-257.

10. Álvarez RL, Zarco QL. Los fenómonos de biostimulatión sexual en ovejas y cabras. Vet-Mex 2001: 32; 117-129.

11. Rosa HJD, Bryant MJ. The 'ram effect' as a way of modifying the reproductive activity in the ewe. Small Rumin Res 2002: 45; 1-16.

12. Geytenbeek PE, Oldham CM, Gray SJ. The induction of ovulation in the post-partum ewe. Anim Prod Aust 1984: 15; 353-356.

13. Pérez-Hernández $\mathbf{P}$, García-Winder $\mathbf{M}$, GallegosSánchez J. Bull exposure and an increased withinday milking to suckling interval reduced postpartum anoestrus in dual purpose cows. Anim Reprod Sci 2002: 74; 111-119.

14. González de Bulnes, A, Santiago Moreno, J, Lípez Sebastión, A. Estimation of fetal development in Manchega dairy ewes by transrectal ultrasonographic measurements. Small Rumin Res 1998: 27; 243-250.

15. Martin GB, Walkden-Brown SW. Nutritional influences on reproduction in mature male sheep and goats. J Reprod Fertil 1995; 49 (Suppl) ; 437-449.

16. Combrink GC, Schoeman SJ. The influence of exercising rams on the lambing performance of a Merino flock. S Afr J Anim Sci 1993: 23; 24-25.

17. Cole HH, Miller RF. Artificial induction of ovulation and estrum in the ewe during anestrum. Am J Physiol 1933: 104; 165-171.

18. Scaramuzzi RJ, Davidson WG, Van Look PFA. The effect of active immunization against androstenedione on oestrus and ovulation in sheep. Nature (London) 1977: 269; 817-818.

19. O'Shea T, Bindon BM, Hillard MA, Piper LR, Findlay JK, Miyamoto K. Increase in ovulation rate in Merino ewes after active immunization with inhibin preparations obtained by immunoaffinity chromatography. Reprod Fertil Dev 1989: 1; 347-355.

20. Scaramuzzi RJ, Radford HM. Factors regulating ovulation rate in the ewe. J Reprod Fertil 1983: 69; 353-367.

21. Scaramuzzi RJ, Baird DT, Campbell BK, Downing JA, Findlay JK, Henderson KM, Martin GB,
McNatty KP, McNeilly AS, Tsonis CG. A model for follicle selection and the determination of ovulation rate in the ewe. Reprod Fertil Dev 1993: 5; 459-478.

22. Stewart R, Oldham CM. Feeding lupins for 4 days during the luteal phase can increase ovulation rate. Anim Prod Aust 1986: 16; 367-370.

23. Restall BJ, Brown GH, Blockey MAdeB, Cahill L, Kearins R. Assessment of reproductive wastage in sheep: 1. Fertilisation failure and early embryo survival. Aust J Exp Agric Anim Husb 1976: 16; 329335.

24. Parr RA, Davis IF, Miles MA, Squires TJ. Liver blood flow and metabolic clearance rate of progesterone in sheep. Res Vet Sci 1993: 55; 311-316.

25. Bloomfield FH, Oliver MH, Hawkins P, Campbell M, Phillips DJ, Gluckman PD, Challis JRG, Harding JE. A periconceptional nutritional origin for noninfectious preterm birth. Science 2003: 300; 606.

26. Bell AW. Factors controlling placental and fetal growth and their effects on future production. In: Lindsay DR, Pearce DT (eds.), Reproduction in Sheep. Cambridge, UK: Cambridge University Press; 1984: 144-152.

27. Nowak R. Neonatal survival: contributions from behavioural studies in sheep. Appl Anim Behav Sci 1996: 49; 61-72.

28. Banchero GE, Quintans G, Milton JTB, Lindsay DR. Supplementation of Corriedale ewes with maize during the last week of pregnancy increases production of colostrum. Anim Prod Aust 2002; 24: 273.

29. Goursaud AP, Nowak R. Colostrum mediates the development of mother preference by the new born lamb. Physiol Behav 1999: 67; 49-56.

30. Goodwin N, Norton BW. Improving doe nutrition immediately prior to kidding increases kid survival. Anim Prod Aust 2004: 25; 233.

31. Murphy PM, Purvis IW, Lindsay DR, Le Neindre P, Orgeur P, Poindron P. Measures of temperament are highly repeatable in Merino sheep and some are related to maternal behaviour. Anim Prod Aust 1994: 20; 247-250.

32. Sart S, Bencini R, Blache D, Martin GB. Calm ewes produce higher quality milk than nervous ewes. Anim Prod Aust 2004: 25; 307. 